\title{
Delivery of a nonpotassium modified maintenance solution to enhance myocardial protection in stressed neonatal hearts: A new approach
}

\author{
Michael T. Kronon, MD* \\ Bradley S. Allen, MD \\ Ari Halldorsson, MD \\ Shaikh Rahman, PhD \\ Mary Jane Barth, MD \\ Michel Ilbawi, MD
}

From The Division of Cardiovascular Surgery, The Heart Institute for Children, Hope Children's Hospital, Oak Lawn, Ill, and The Division of Cardiothoracic Surgery, The University of Illinois of Chicago, Chicago, Ill.

Read at the Twenty-sixth Annual Meeting of The Western Thoracic Surgical Association, The Big Island of Hawaii, June 21-25, 2000.

Received for publication Sept 13, 2000; revisions requested Feb 2, 2001; revision received June 6, 2001; accepted for publication July 27, 2001

Address for reprints: Bradley S. Allen, MD The Heart Institute for Children, Hope Children's Hospital, 4440 W 95th St, Oak Lawn, IL 60453.

*Supported in part by the Pillsbury Fellowship.

J Thorac Cardiovasc Surg 2002;123:119-29

Copyright (C) 2002 by The American Association for Thoracic Surgery.

$0022-5223 / 2002 \$ 35.00+0 \quad \mathbf{1 2 / 6 / 1 1 9 6 9 3}$

doi:10.1067/mtc.2002.119693
Objectives: This study was undertaken to compare conventional cardioplegic strategies with a new approach that uses a modified nonpotassium maintenance solution between cardioplegia doses in stressed neonatal hearts.

Methods: Thirty-five neonatal piglets underwent 60 minutes of ventilator hypoxia (inspired oxygen fraction $8 \%-10 \%$ ) followed by 20 minutes of ischemia on cardiopulmonary bypass. In 10 animals bypass was discontinued without further ischemia (stress control group). The other 25 received a warm blood cardioplegic induction and were separated into 5 groups. In 5 animals cardiopulmonary bypass was discontinued without further ischemia (cardioplegia control group); the remaining 20 underwent an additional 70 minutes of cold blood cardioplegic arrest. Five received only intermittent cardioplegia every 20 minutes, whereas 15 also received cold blood maintenance infusions between cardioplegic doses (integrated strategy). In 5 of these animals the blood was unmodified, whereas in 10 a modified nonpotassium "cardioplegia-like" solution was delivered either antegradely $(n=5)$ or retrogradely $(\mathrm{n}=5)$. Myocardial function was assessed by pressure-volume loops (expressed as percentage of control); vascular function was assessed by coronary vascular resistance.

Results: All piglets that underwent hypoxic ischemic stress alone (controls) died. Warm induction alone (cardioplegic controls) partially repaired the stress injury. Intermittent cardioplegia preserved the depressed systolic function (end-systolic elastance $40 \%$ vs $39 \%$ ), increased diastolic stiffness (255\% vs $239 \%$ ), reduced adenosine triphosphate ( 10.6 vs $12.2 \mu \mathrm{g} / \mathrm{g}$ tissue), and elevated coronary vascular resistance at levels identical to warm induction alone; infusing unmodified blood between cardioplegia doses (standard integrated) improved results slightly. In contrast, infusion of a cold modified solution (antegrade or retrograde) between cardioplegia doses (modified integrated) completely restored systolic function (end-systolic elastance $100 \%$ and $97 \%, P<.001$ vs intermittent and standard integrated), only minimally increased diastolic stiffness $(159 \%$ and $156 \%, P<.001$ vs intermittent and standard integrated), restored adenosine triphosphate (18.8 and $16.6 \mu \mathrm{g} / \mathrm{g}, P<.001$ vs intermittent and standard integrated), and normalized coronary vascular resistance $(P<.001$ vs intermittent and standard integrated). This strategy was used in 72 consecutive hypoxic patients $(21$ arterial switch operations, retrograde; 51 Fontan procedures, antegrade) with a $2.8 \%$ mortality.

Conclusions: Infusion of a cold modified solution between cardioplegic doses (modified integrated protection) significantly improved myocardial protection in the stressed neonatal heart, was effective delivered either antegradely or retrogradely, and was used successfully for hypoxic (stressed) pediatric patients. 


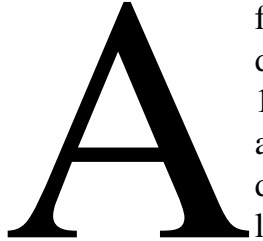

fter cardioplegic arrest, most surgeons deliver intermittent cardioplegia every 15 to 20 minutes to maintain myocardial arrest, restore hypothermia, buffer acidosis, and wash away acid metabolites. ${ }^{1,2}$ This is traditional, but a dry field is not always required between cardioplegic doses. To further limit ischemia and improve protection, we introduced the concept of integrated cardioplegia, which consists of infusing a maintenance solution of unmodified cold $\left(4^{\circ} \mathrm{C}\right)$ blood between intermittent cardioplegic doses whenever visualization is not impaired by coronary perfusion. 1,3,4 Cold unmodified blood is used for the maintenance infusions; because hypothermia alone tends to keep the heart arrested, it allows the infusions to be safely interrupted when a dry field is required for optimal visualization, and it avoids administration of large quantities of potassium. Despite excellent clinical results in adult patients, the standard integrated strategy has never been evaluated experimentally and is rarely used in pediatric patients. ${ }^{1,3,4}$ Indeed, several studies in pediatric hearts have suggested that multiple intermittent cardioplegic infusions are no better, and may even be worse, than a single cold infusion. ${ }^{2,5,6}$

Postoperative myocardial dysfunction, however, remains the primary cause of morbidity and mortality in pediatric patients, occurring most frequently in the presence of cyanosis. ${ }^{2,6-9}$ Hypoxia is associated with metabolic adaptations that allow normal aerobic metabolism to persist in the resting state. However, this compensatory mechanism is expended readily with stress, as atrial pacing or catecholamine infusion causes myocardial lactate production, indicating ischemia with a shift toward anaerobic metabolism. ${ }^{10,11}$ This metabolic shift may occur in cyanotic patients during the stresses of daily life, such as exercise, emotional upset, and tachycardia, and may become compounded during anoxic spells. Hypoxic hearts are also more vulnerable to accelerated depletion of adenosine triphosphate (ATP) during surgical ischemia, as well as predisposed toward reoxygenation injury with the reintroduction of oxygen..$^{5,8,12}$ Consequently, the cyanotic pediatric heart is more vulnerable than the normoxic adult heart to inadequacies in myocardial protection and might derive an even greater benefit from an integrated approach that limits ischemia.

To parallel this experimentally, we used stressed (hypoxic and ischemic) neonatal hearts to evaluate the conventional techniques of intermittent cardioplegia and standard integrated protection. The standard integrated strategy has the potential problem of producing a reperfusion injury, however, because it exposes the ischemic heart to multiple infusions of cold unmodified blood, which Rebeyka and associates ${ }^{13}$ have shown is dangerous in infants. We therefore also evaluated a new approach, which replaces the cold unmodified blood with a cold modified (nonpotassium, magnesium-enriched, citrate-phosphate-dextrose, tromethamine) blood solution. We termed this the "modified integrated strategy." Use of a modified nonpotassium "cardioplegia-like" blood solution for the maintenance infusions has the potential advantage of reducing any reperfusion injury, because cardioplegia limits reperfusion damage after ischemia, and the heart is ischemic between cardioplegic doses. ${ }^{1,14,15}$ Hyperkalemia is avoided by not adding potassium, and the heart is kept arrested by hypothermia as well as by changes in magnesium and calcium. To more closely mimic clinical experience, we also determined whether the method of delivery (antegrade vs retrograde) affected results. This simulates operations such as the arterial switch procedure, where antegrade perfusion is not possible after the initial cardioplegia dose. On the basis of the experimental infrastructure provided by these studies, we incorporated a modified integrated strategy into our clinical practice and examined the results in 72 high-risk patients (Fontan and arterial switch procedures).

\section{Methods}

Thirty-five neonatal (5- to 18 -day-old) piglets ( 3.5 to $5 \mathrm{~kg}$ ) were intramuscularly medicated with $40 \mathrm{mg} / \mathrm{kg}$ ketamine, were intraperitoneally anesthetized with $30 \mathrm{mg} / \mathrm{kg}$ phenobarbital followed by 5 $\mathrm{mg} / \mathrm{kg}$ intravenously each hour, and had the lungs ventilated through a tracheotomy with a volume ventilator (Servo 900B; Siemens/ Elema, Solna, Sweden). All animals received humane care in compliance with the "Principles of Laboratory Animal Care" formulated by the National Society for Medical Research, and "Guide for the Care and Use of Laboratory Animals," prepared by the National Academy of Sciences and published by the National Institutes of Health (NIH), Publication No. 96-03, Revised 1996. The experimental preparation, including cannulation for bypass, the bypass prime, and blood sample procurement, was comparable with that previously described elsewhere. $5,12,16$

\section{Experimental Protocols}

Hypoxic-ischemic stress. All 35 piglets underwent 60 minutes of ventilator hypoxia by lowering the fraction of inspired oxygen to $8 \%$ to $10 \%$ to produce an arterial $\mathrm{Po}_{2}$ of 25 to $35 \mathrm{~mm} \mathrm{Hg}$ and an oxygen saturation of $65 \%$ to $70 \%$. Before hypoxemia, piglets were transfused as necessary to increase the hematocrit to greater than $35 \%$. This simulated the chronic adaptive change of erythrocytosis and increased oxygen-carrying capacity, thereby allowing ischemia to be avoided during hypoxia., 52,16 At the end of 60 minutes, piglets were placed on cardiopulmonary bypass (CPB) at an inspired oxygen fraction of $100 \%$ for 5 minutes to produce a reoxygenation injury. The aorta was then clamped for 20 minutes at $37^{\circ} \mathrm{C}$ to add a normothermic ischemic injury to the hypoxic stress.

Hypoxic-ischemic (stress) controls. Ten piglets served as controls for the hypoxic-ischemic stress. Five underwent myocardial biopsy to determine the biochemical changes; the other 5 had the aortic clamp removed and CPB continued for 60 minutes without further ischemia to determine the functional changes. The remaining 25 piglets underwent cardioplegic arrest according to the protocol described in the next section. 
TABLE 1. Warm blood cardioplegia solution

\begin{tabular}{lccc}
\hline Cardioplegia additive & Volume added $(\mathrm{mL})$ & Component modified & Concentration delivered* $^{*}$ \\
\hline Potassium chloride $(2 \mathrm{mEq} / \mathrm{mL})$ & 10 & Potassium ion & $8-10 \mathrm{mEq} / \mathrm{L}$ \\
Tromethamine $(0.3 \mathrm{~mol} / \mathrm{L})$ & 225 & $\mathrm{pH}$ & $\mathrm{pH} 7.5-7.7$ \\
Citrate-phosphate-dextrose & 225 & Calcium ion & $0.2-0.4 \mathrm{mmol} / \mathrm{L}$ \\
Aspartate, glutamate & 250 & Substrate & $13 \mathrm{mmol} / \mathrm{L}$ each \\
$50 \%$ Dextrose in water & 40 & Glucose & $<400 \mathrm{mg} / \mathrm{dL}$ \\
$5 \%$ Dextrose in water & 200 & Osmolarity & $380-400 \mathrm{m0sm}$ \\
\hline
\end{tabular}

*When mixed in a 4:1 ratio with blood.

TABLE 2. Cold multidose blood cardioplegia solution

\begin{tabular}{lccc}
\hline Cardioplegia additive & Volume added $(\mathrm{mL})$ & Component modified & Concentration delivered* $^{*}$ \\
\hline Potassium chloride $(2 \mathrm{mEq} / \mathrm{mL})$ & 10 & Potassium ion & $8-10 \mathrm{mEq} / \mathrm{L}$ \\
Tromethamine $(0.3 \mathrm{~mol} / \mathrm{L})$ & 200 & $\mathrm{pH}$ & $\mathrm{pH} 7.6-7.8$ \\
Citrate-phosphate-dextrose & 50 & Calcium ion & $0.5-0.6 \mathrm{mmol} / \mathrm{L}$ \\
$5 \%$ Dextrose in water $1 / 4$ isotonic saline solution & 550 & 0 Osmolarity & $340-360 \mathrm{~m} 0 \mathrm{sm}$
\end{tabular}

*When mixed in a 4:1 ratio with blood.

\section{TABLE 3. Modified cold blood maintenance solution}

\begin{tabular}{lclc}
\hline Solution additive & Volume added $(\mathrm{mL})$ & \multicolumn{1}{c}{ Component modified } & Concentration delivered $^{*}$ \\
\hline Tromethamine $(0.3 \mathrm{~mol} / \mathrm{L})$ & 50 & $\mathrm{pH}$ & $\mathrm{pH} 7.5-7.6$ \\
Citrate-phosphate-dextrose & 50 & Calcium ion & $0.5-0.6 \mathrm{mmol} / \mathrm{L}$ \\
Magnesium chloride $(2 \mathrm{mEq} / \mathrm{mL})$ & 10 & Magnesium ion & $4-6 \mathrm{mg} / \mathrm{L}$ \\
$5 \%$ Dextrose in water $1 / 4$ isotonic saline solution & 1000 & Osmolarity, glucose & $340-360 \mathrm{mOsm}$ \\
Mannitol $(25 \%)$ & 50 & Osmolarity, oxygen radical scavenger & $340-360 \mathrm{~m} 0 \mathrm{sm}$ \\
\hline
\end{tabular}

${ }^{*}$ When mixed in a 4:1 ratio with blood.

Cardioplegic administration. Cardioplegic solutions (CAPS Service; Research Medical Inc, Salt Lake City, Utah) are shown in Tables 1, 2, and 3. Cardioplegic solution was delivered according to a protocol consisting of 5 minutes of warm $\left(37^{\circ} \mathrm{C}\right)$ induction (Table 1) followed by 4 minutes of cold multidose cardioplegia (Table 2), a 2-minute cold multidose infusion every 20 minutes, and a 4-minute warm $\left(37^{\circ} \mathrm{C}\right)$ cardioplegic reperfusate ("hot shot") before aortic unclamping. In groups 1 through 4 all cardioplegic infusions were delivered antegradely, whereas in group 5 the cardioplegic solution was delivered by a combination of antegrade and retrograde routes. Antegrade infusions were always delivered at a continuously measured aortic root pressure of 40 to $50 \mathrm{~mm}$ $\mathrm{Hg}$, and retrograde infusions were delivered at a continuously measured coronary sinus pressure of 30 to $50 \mathrm{~mm} \mathrm{Hg}$. Immediately after the start of cardioplegia, piglets were cooled to a systemic temperature of $26^{\circ} \mathrm{C}$, and warming to $37^{\circ} \mathrm{C}$ was begun 16 minutes before aortic unclamping. All piglets undergoing cardioplegic arrest were weaned from CPB with no inotropic support 30 minutes after aortic unclamping. After arterial blood gases, calcium ion, and potassium ion were normalized, final functional and biochemical measurements were made 30 minutes later.

\section{Cardioplegia Groups}

After the hypoxic-ischemic stress, the 25 piglets undergoing cardioplegic arrest received a warm induction and were divided into 5 groups. Group 1 piglets did not undergo any further ischemia, whereas groups 2 through 5 underwent 70 minutes of cardioplegic arrest.

Warm induction alone (group 1, cardioplegic controls). Five piglets received warm blood cardioplegic induction and then had the aortic crossclamp removed immediately to determine the effect of warm induction without any further ischemia. These piglets therefore acted as a cardioplegic control group, because all subsequent cardioplegia groups (groups 2-5) also received a warm induction.

Intermittent cardioplegia (group 2). To test the intermittent cardioplegic protection strategy, 5 piglets underwent 70 minutes of ischemic arrest with warm induction followed by cold intermittent cardioplegia every 20 minutes and a warm reperfusate according to the protocol detailed previously.

Integrated strategy (groups 3 through 5). During the 20minute intervals between cardioplegic doses, the surgeon does not always require a dry field for optimal visualization. At these times the heart can be perfused to reduce ischemia. To test this strategy 
(integrated approach), 15 piglets received a maintenance infusion of either unmodified blood (standard integrated strategy, group 3) or a modified nonpotassium blood solution (modified integrated strategy, groups 4 and 5), for the 10 minutes (half the time) immediately before each intermittent cardioplegic infusion. These piglets therefore underwent 10 minutes of ischemia followed by a 10-minute maintenance infusion and then the cardioplegia dose.

Standard integrated strategy (group 3). To test the standard integrated myocardial protection strategy, 5 piglets received maintenance infusions (between cardioplegic doses) with unmodified blood from the bypass circuit by removing the cardioplegic line from the pump head.

Modified integrated strategy (groups 4 and 5). Unmodified blood can potentially cause a reperfusion injury because the heart is ischemic between cardioplegic doses and as Rebeyka showed unmodified blood can be detrimental in infants. ${ }^{1,2,13,14}$ A modified cardioplegia-like solution might help limit this injury. To test this new approach, the integrated strategy was modified in 10 piglets by infusing a cold modified nonpotassium blood maintenance solution (Table 3) in place of unmodified blood. The method of delivery was also evaluated, because it is not always possible to deliver antegrade cardioplegia (such as in the arterial switch operation).

Antegrade delivery (group 4). In 5 piglets the modified maintenance solution as well as all cardioplegic infusions were delivered antegradely.

Retrograde delivery (group 5). In 5 piglets retrograde delivery was used for the cold modified maintenance infusions as well as the intermittent cold cardioplegic doses. Warm induction and the terminal cardioplegic reperfusate were given antegradely. This examined the effectiveness of the modified integrated strategy for patients in whom antegrade infusions cannot be delivered for part of the procedure (such as those undergoing arterial switch or aortic valve repair).

\section{Myocardial Performance}

Left ventricular pressure and conductance catheter signals were amplified and digitized to inscribe left ventricular pressurevolume loops after first correcting for parallel conductance (myocardial tissue and blood viscosity) with hypertonic saline solution as previously described. ${ }^{5,16}$ Measurements were made before hypoxia (baseline) and 30 minutes after CPB was discontinued. The end-systolic and end-diastolic pressure-volume relationship and preload recruitable stroke were analyzed with the use of a computer graphics program (Spectrum; Bowman-Gray School of Medicine, Winston-Salem, NC), as previously described. ${ }^{5,12,16}$ Functional measurements are expressed as percentage recovery of baseline values, with each piglet acting as its own control. After final hemodynamic measurements, all piglets were placed back on bypass, and transmural left ventricular biopsy specimens were obtained for biochemical analysis, with a separate sample obtained for myocardial water determination as previously described.

\section{Physiologic Measurements}

Coronary vascular resistance (CVR) was determined during each antegrade cardioplegic infusion by measuring coronary sinus pressure and cardioplegic flow once a constant infusion rate with an aortic root pressure between 40 and $50 \mathrm{~mm} \mathrm{Hg}$ was achieved. CVR was calculated as previously described as the change in pres- sure across the coronary vascular bed divided by the cardioplegia flow rate, multiplied by 80 , and expressed as dynes $\cdot \mathrm{s} \cdot \mathrm{cm}^{-5} .5,16$

\section{Myocardial Oxygen Consumption}

Blood was obtained at 1-minute intervals from the cardioplegia line and coronary sinus across the 4 minutes of warm reperfusion (hot shot, groups 2-5), and myocardial oxygen consumption was determined as previously described elsewhere. ${ }^{17}$ The cumulative myocardial oxygen consumption was determined by the sum of the individual 1-minute values and expressed per $100 \mathrm{~g}$ of heart tissue, which was determined by weighing the left ventricle at the conclusion of the experiment.

\section{Biochemical Analysis}

Adenosine pool. Myocardial samples were crushed in a liquid nitrogen-cooled mortar and pestle and lyophilized (Savant Speed Vac Systems, Farmingdale, NY). The adenosine pool was determined as described previously, and ATP levels were expressed as micrograms per gram dry tissue..$^{5,16}$

Myeloperoxidase activity. Quantitative myeloperoxidase activity was determined as described previously and is expressed as the change in optical density units per minute per milligram of tissue protein $\left(\Delta \mathrm{OD} \cdot \mathrm{min}^{-1} \cdot \mathrm{mg}^{-1}\right.$ protein $) .{ }^{17}$

Antioxidant reserve capacity. Myocardial antioxidant reserve capacity (AORC) was assessed as previously described by determining the in vitro lipid peroxidation in cardiac tissue that was homogenized and incubated with t-butylhydroperoxide at a concentration of $4 \mathrm{mmol} / \mathrm{L} .{ }^{12}$ AORC was expressed as malondialdehyde production in nanomoles per gram of heart tissue protein. The higher the production of malondialdehyde to the oxidant stress (t-butylhydroperoxide), the lower the tissue AORC, indicating depletion of antioxidants secondary to exposure of the heart to oxygen-derived free radicals during reperfusion.

Conjugated diene production. Blood was obtained from the cardioplegia line and coronary sinus 1 and 4 minutes after starting warm reperfusion (hot shot) in groups 2 through 5 , and conjugated dienes were assessed as previously described elsewhere. ${ }^{17}$ Conjugated diene production was expressed per $100 \mathrm{~g}$ of heart tissue by weighing the left ventricle at the conclusion of the experiment.

Myocardial water. Ventricular samples were placed in preweighed vials and dried to a constant weight at a temperature of $85^{\circ} \mathrm{C}$. The percentage of myocardial water was calculated according to the following formula: percentage of myocardial water $=$ [(wet weight - dry weight $) /$ wet weight $] \times 100 \%$.

\section{Clinical Studies}

The charts of all neonates undergoing an arterial switch operation within the first month of life and of infants undergoing a modified lateral-tunnel Fontan procedure at the University of Illinois or The Heart Institute for Children from July 1, 1996, to December 31, 1998, were retrospectively reviewed. The starting date was chosen because this is when we began to use a modified integrated strategy when applicable in adult and pediatric patients. The clinical cardioplegia protocol consisted of cold induction, followed by cold multidose infusions every 10 to 15 minutes, and finally a substrateenriched terminal warm reperfusate before removal of the aortic crossclamp. A cold modified (nonpotassium) blood maintenance solution was infused continuously whenever it did not impair opti- 


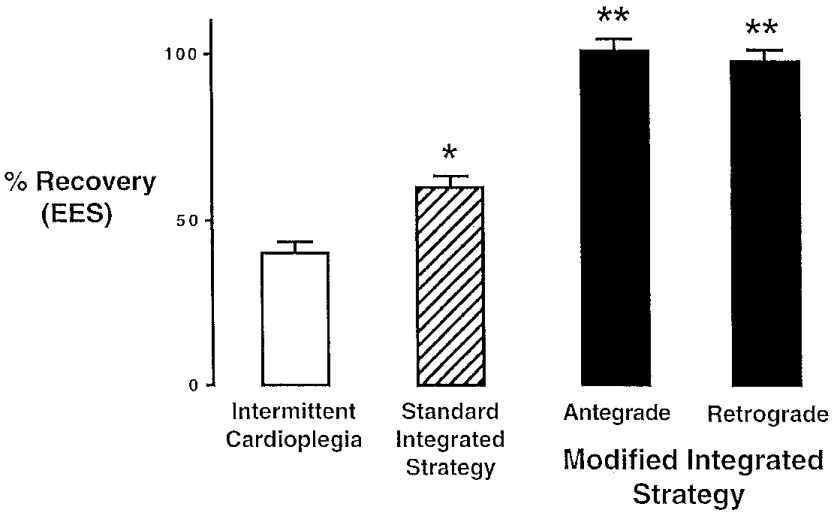

Figure 1. Postbypass left ventricular contractile function after 70 minute cardioplegic arrest. Recovery of left ventricular systolic function as measured by end-systolic elastance (EES) and expressed as percentage of control (baseline). Exposing the heart to hypoxia and ischemia produced such severe stress that warm induction blood cardioplegia was only able to partially resuscitate the heart. Intermittent cardioplegia preserved function at these same levels despite addition of $\mathbf{7 0}$ minutes of ischemic arrest. In contrast, adding maintenance infusions of unmodified cold blood (standard integrated strategy) further resuscitated the heart and improved contractility. However, this effect was maximized if modified solution was used for the maintenance infusions (modified integrated strategy), resulting in complete return of systolic function. Asterisk indicates $\boldsymbol{P}<.001$ versus intermittent cardioplegia; double asterisk indicates $P<.001$ versus all other groups.

mal visualization. In Fontan procedures, all infusions were given in an antegrade fashion. In arterial switch operations, the cardioplegic induction was delivered antegradely. Thereafter, all cold intermittent cardioplegia and maintenance (modified solution) infusions were delivered retrogradely, because antegrade delivery is impossible with the aorta divided. However, all patients undergoing arterial switch received an antegrade (terminal) warm blood cardioplegic reperfusate before removal of the aortic crossclamp.

\section{Statistics}

Data were analyzed with JMP V2.0 (SAS Institute, Inc, Cary, NC) on a Macintosh IIVX computer (Apple Computer, Inc, Cupertino, Calif). Paired Student $t$ tests with 1-way analysis of variance were used for comparison of variables among experimental groups. If the analysis of variance revealed a significant interaction, pairwise tests of individual group means were compared by means of multiple comparisons (Tukey test) at significance levels of $P<.05, P$ $<.01$, and $P<.001$. Group data are expressed as mean \pm SEM.

\section{Results}

There was no statistically significant difference $(P>.2)$ between groups for baseline (prehypoxic) values (slopes) of left ventricular contractility (end-systolic elastance $35 \pm 2$ $\mathrm{mm} \mathrm{Hg} / \mathrm{mL})$, diastolic compliance $(0.04 \pm 0.01)$, or preload recruitable stroke work $\left(68 \pm 3 \int[\mathrm{mm} \mathrm{Hg} \cdot \mathrm{mL}] / \mathrm{mL}\right)$.

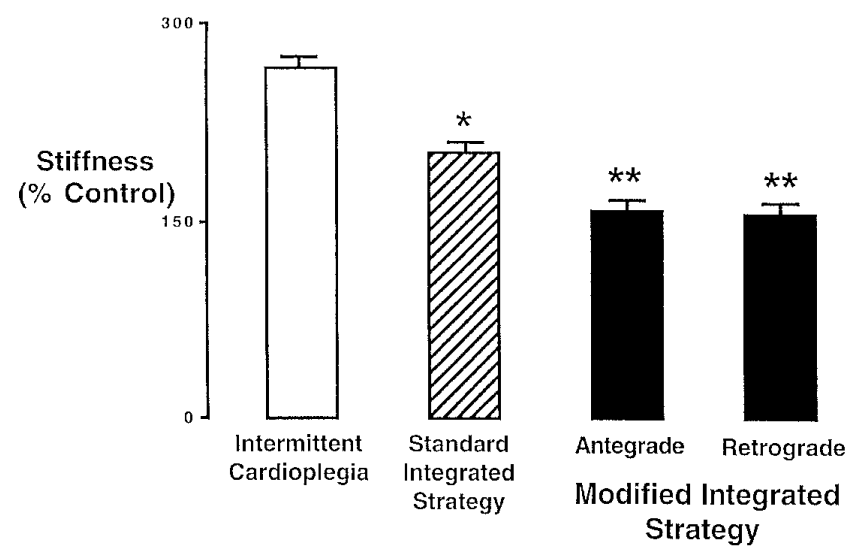

Figure 2. Postbypass left ventricular diastolic compliance after 70-minute cardioplegic arrest, as measured by end-diastolic pressure volume relationship and expressed as percentage of stiffness compared with control (baseline). Asterisk indicates $\boldsymbol{P}<.001$ versus intermittent cardioplegia; double asterisk indicates $P<$ .001 versus all other groups.

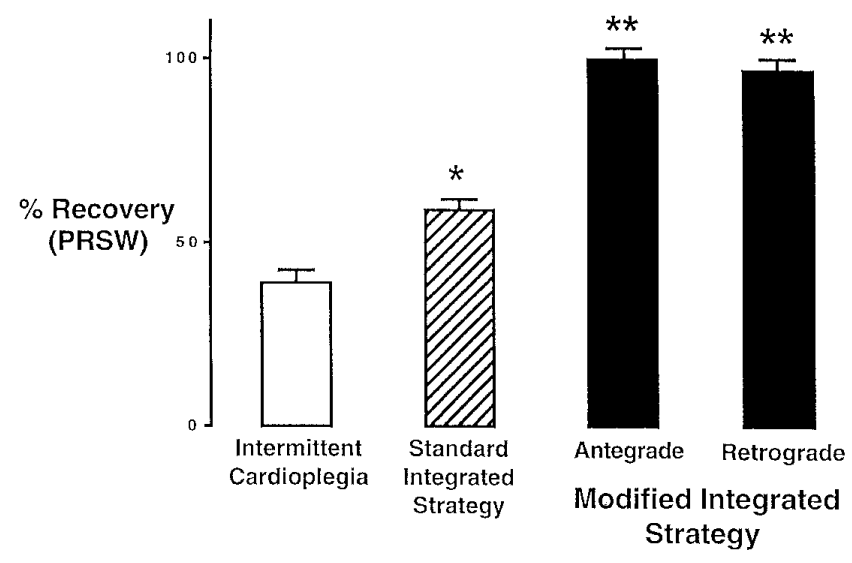

Figure 3. Recovery of overall myocardial function as measured by preload recruitable stroke work (PRSW) and expressed as percentage of control (baseline). Asterisk indicates $P<.001$ versus intermittent cardioplegia; double asterisk indicates $\boldsymbol{P}<.001$ versus all other groups.

Hemodynamic and Physiologic Measurements

Results are depicted in Figures 1 through 4. There were no significant changes or differences $(P>.2)$ in the $\mathrm{x}$-axis intercept $\left(\mathrm{V}_{0}\right)$ for end-systolic elastance or preload recruitable stoke work between prebypass (baseline) and postbypass values in any cardioplegic group. Therefore, the change in slope of end-systolic elastance and preload recruitable stroke work could be interpreted to represent variability in the contractile state of the myocardium relative to baseline values. This also allowed the change in 


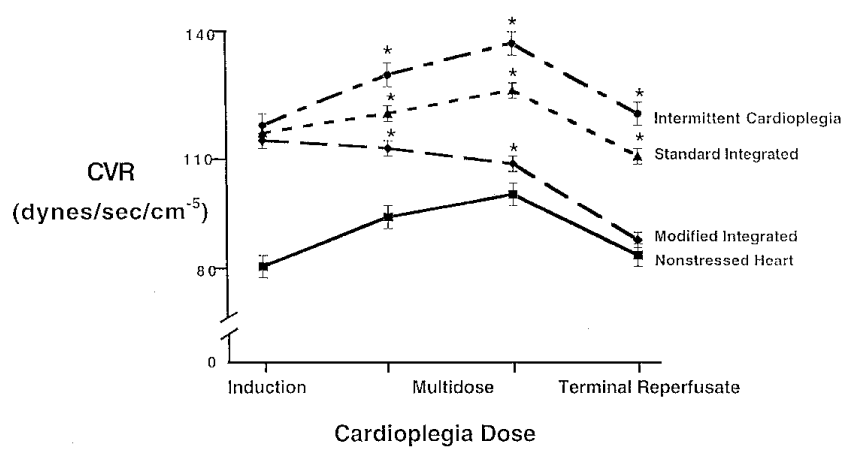

Figure 4. CVR measured during each antegrade cardioplegic infusion. Piglets receiving retrograde delivery of modified solution (group 5) only had CVR measured during warm induction and reperfusion, and these values were not different from those of piglets receiving antegrade infusions (group 4). Solid line depicts CVR in 6 normal (nonstressed) piglets subjected to 70 minutes of cardioplegic arrest with same cardioplegic protocol (warm induction, multidose cold intermittent cardioplegia, and warm reperfusion). This line therefore represents normal CVR with no vascular dysfunction from stress (hypoxic) injury. After hypoxic-ischemic stress, CVR is increased and remains high with intermittent cardioplegia alone, suggesting vascular injury. However, CVR declines toward normal if maintenance infusions are delivered between cardioplegic doses (integrated strategy), and this effect is maximized if modified solution is used for infusions (see text for details). Data points represent mean; error bars represent SE. Single asterisk indicates $\boldsymbol{P}<.001$ versus all other groups.

slope to be expressed as a percentage of baseline, with each piglet acting as its own control. The combination of hypoxia and ischemia caused such a severe injury that bypass could not be discontinued in piglets not receiving cardioplegia (hypoxic-ischemic controls), despite an additional $60 \mathrm{~min}$ utes of CPB support. Thus no postbypass functional measurements could be obtained in these piglets. In contrast, warm induction without ischemia (group 1, cardioplegic controls) partially resuscitated the hypoxic-ischemic myocardium, thereby allowing bypass to be discontinued. However, these piglets still had depressed postbypass systolic contractility (end-systolic elastance 39\% $\pm 3 \%$ ), markedly increased diastolic stiffness $(271 \% \pm 8 \%)$, and reduced preload recruitable stroke work $(40 \% \pm 2 \%)$. Adding 70 minutes of cardioplegic ischemia with multidose cold intermittent cardioplegic infusions (group 2) preserved but did not improve myocardial function, as it was identical $(P>.2)$ to hearts receiving warm cardioplegia without further ischemia (group 1). In contrast, postbypass function was slightly improved if a maintenance solution of cold unmodified blood (standard integrated protection) was given for 10 minutes between intermittent cardioplegic infusions (group 3). However, there was complete func- tional recovery if the maintenance infusions used a modified nonpotassium blood solution (modified integrated strategy). These improved results were independent of whether the modified solution was infused antegradely (group 4) or retrogradely (group 5). CVR followed a similar trend. The CVR decreased to normal when the heart was protected with a modified integrated strategy, delivered either antegradely or retrogradely (groups 4 and 5).,16 Piglets that received retrograde delivery (group 5), however, only had CVR determined during warm induction and reperfusion, because CVR measurements were made during antegrade infusions. In contrast, the CVR remained elevated in groups 2 (intermittent) and 3 (standard integrated strategy), although there was a slight improvement (decrease) in piglets receiving maintenance infusions of unmodified blood (standard integrated strategy).

\section{Biochemical Studies}

Results are summarized in Table 4. Compared with levels at the end of the hypoxic-ischemic stress, warm blood cardioplegia induction alone (group 1) improved the biochemical markers of injury. However, there was still a significant oxidant injury, as documented by the decreased tissue AORC. The myeloperoxidase activity was increased, and the ratio of ATP to adenosine diphosphate (ADP), which measures the ability of the mitochondria to phosphorylate ADP to ATP and is an indirect measurement of mitochondrial function, was decreased. Intermittent cold blood cardioplegia maintained energy levels (ATP) and mitochondrial function (ATP/ADP ratio) and prevented a further oxidant injury (no change in AORC), despite an additional 70 minutes of ischemia. Mitochondrial dysfunction (low ATP/ADP ratio) prevented replenishment of ATP levels and probably explains the lower oxygen uptake during reperfusion. In contrast, infusion of unmodified cold blood between cardioplegia infusions (standard integrated strategy) partially improved all metabolic markers. By reducing the oxidant injury, mitochondrial function was partially restored (improved ATP/ADP ratio), which allowed ATP levels to be increased, resulting in higher oxygen uptake during reperfusion. However, infusion of a maintenance solution of modified nonpotassium blood between cardioplegia doses (modified integrated strategy) completely resuscitated the heart, preventing oxidant injury (lower conjugated dienes) and restoring AORC, mitochondrial function (ATP/ADP ratio), and energy levels (ATP). As with the functional data, the method of delivery was unimportant, because there were no differences between antegrade and retrograde infusions. The myocardial water (edema) and myeloperoxidase activity, which are both indirect measurements of cellular injury, were also reduced with a modified integrated strategy (groups 4 and 5), further supporting decreased cellular damage in these hearts. 
TABLE 4. Myocardial oxygen consumption and biochemical results

\begin{tabular}{|c|c|c|c|c|c|c|c|c|}
\hline \multirow[b]{2}{*}{ Group } & \multirow{2}{*}{$\begin{array}{c}\text { Myocardial } \\
\text { oxygen } \\
\text { consumption* } \\
\text { (mL/100 g/4 min) }\end{array}$} & \multicolumn{2}{|c|}{$\begin{array}{c}\text { Conjugated } \\
\text { diene production* } \\
\text { (OD/ } / \mathrm{mL} \cdot 100 \mathrm{~g} \cdot \mathrm{min})\end{array}$} & \multirow{2}{*}{$\begin{array}{c}\text { AORC† } \\
\text { malondialdehyde } \\
\text { (nm/g protein) }\end{array}$} & \multirow{2}{*}{$\begin{array}{l}\text { ATP }(\mu \mathrm{g} / \mathrm{g} \\
\text { dry weight) }\end{array}$} & \multirow{2}{*}{$\begin{array}{l}\text { ATP/ADP } \\
\text { ratio }\end{array}$} & \multirow{2}{*}{$\begin{array}{c}\text { Myocardial } \\
\text { water (\%) }\end{array}$} & \multirow{2}{*}{ 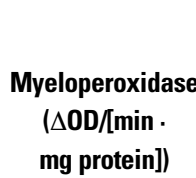 } \\
\hline & & 1 min & $4 \min$ & & & & & \\
\hline $\begin{array}{l}\text { Hypoxic-ischemic } \\
\text { stress }(n=5)\end{array}$ & - & - & - & $1441 \pm 24$ & $8.2 \pm 0.3$ & $1.1 \pm 0.2$ & $80.1 \pm 0.1$ & $2.4 \pm 0.2$ \\
\hline $\begin{array}{l}\text { Warm induction alone } \\
\quad \text { (group } 1, n=5)\end{array}$ & - & - & - & $1229 \pm 22 \ddagger$ & $10.7 \pm 0.2 \ddagger$ & $1.8 \pm 0.1 \mp$ & $80.8 \pm 0.1 \ddagger$ & $1.9 \pm 0.1 \ddagger$ \\
\hline $\begin{array}{l}\text { Intermittent } \\
\quad \text { cardioplegia } \\
\text { (group 2, n=5) }\end{array}$ & $4.3 \pm 0.3$ & $57 \pm 2$ & $60 \pm 1$ & $1216 \pm 26 \ddagger$ & $10.8 \pm 0.4 \ddagger$ & $2.0 \pm 0.2 \ddagger$ & $80.7 \pm 0.1 \ddagger$ & $1.8 \pm 0.1 \ddagger$ \\
\hline $\begin{array}{l}\text { Standard integrated } \\
\text { strategy (group 3, } \\
n=5 \text { ) }\end{array}$ & $6.5 \pm 0.1 \S$ & $37 \pm 1 \S$ & $40 \pm 2 \S$ & $1045 \pm 20$ & $13.6 \pm 0.3$ & $2.9 \pm 0.2$ & $80.2 \pm 0.1 \|$ & $1.3 \pm 0.1$ \\
\hline $\begin{array}{l}\text { Modified integrated } \\
\text { strategy, antegrade } \\
\text { (group } 4, n=5 \text { ) }\end{array}$ & $8.4 \pm 0.2 \rrbracket$ & $17 \pm 29$ & $19 \pm 2 \uparrow$ & $861 \pm 18 \pi$ & $16.4 \pm 0.5 n$ & $3.7 \pm 0.29$ & $79.5 \pm 0.1 \rrbracket$ & $0.8 \pm 0.27$ \\
\hline $\begin{array}{l}\text { Modified integrated } \\
\text { strategy, retrograde } \\
\text { (group } 5, n=5 \text { ) }\end{array}$ & $8.6 \pm 0.2 \pi$ & $18 \pm 19$ & $20 \pm 2 \rrbracket$ & $874 \pm 16 \pi$ & $16.5 \pm 0.4 \uparrow$ & $3.9 \pm 0.29$ & $79.4 \pm 0.29$ & $0.9 \pm 0.11$ \\
\hline $\mathrm{F}$ & 179 & 305 & 315 & 238 & 162 & 71.4 & 35.6 & 52 \\
\hline$P$ value & $<.001$ & $<.001$ & $<.001$ & $<.001$ & $<.001$ & $<.001$ & $<.001$ & $<.001$ \\
\hline
\end{tabular}

*During warm cardioplegic reperfusion ("hot shot").

tMalondialdehyde production at 4-mmol/L t-butylhydroperoxide.

$\ddagger P<.001$ versus hypoxic-ischemic stress.

$\S P<.001$ versus group 2.

$\| P<.001$ versus groups 1 and 2.

$\Uparrow P<.001$ versus groups 1,2 , and 3 .

\section{Clinical Studies}

There were 72 patients, 51 undergoing a Fontan operation and 21 an arterial switch procedure. The overall mortality was $2.8 \%$ (2/72), with 1 death in each group. In the Fontan group the mean age was $40 \pm 7$ months (range 7-219 months), and the preoperative diagnoses were diverse. Fifteen patients had undergone a previous Norwood procedure, and 27 had undergone a bidirectional Glenn shunt. Among patients undergoing an arterial switch operation, the mean age was $7 \pm 1$ days (range 2-24 days), and all had the diagnosis of dextro-transposition, 4 with a ventricular septal defect. The bypass, crossclamp, and ischemic times, as well as postoperative length of stay and mortality, are listed in Table 5 .

\section{Discussion}

With an in vivo, clinically applicable animal model, this study demonstrates (1) that the conventional techniques of intermittent multidose blood cardioplegia alone or with maintenance infusions of cold unmodified blood (standard integrated strategy) provides inadequate protection of the stressed (hypoxic-ischemic) neonatal heart, (2) that infusion
TABLE 5. Postoperative clinical results

\begin{tabular}{lcc}
\hline Variable & Fontan $(\mathbf{n}=\mathbf{5 1})$ & Arterial switch $(\mathbf{n}=\mathbf{2 1})$ \\
\hline Bypass time (min) & $164 \pm 7(88-274)$ & $204 \pm 9(151-304)$ \\
Crosscamp time $(\mathrm{min})$ & $98 \pm 5(43-200)$ & $102 \pm 4(79-141)$ \\
Ischemic time (min) & $24 \pm 4(2-95)$ & $27 \pm 3(10-65)$ \\
Postoperative stay (d) & $8.4 \pm 0.5(5-18)$ & $10.6 \pm 1.1(5-27)$ \\
Mortality & $1 / 51(2 \%)$ & $1 / 21(4.7 \%)$
\end{tabular}

Ischemic time represents time that the crossclamp is on and there is no myocardial perfusion (neither antegrade nor retrograde).

of a cold modified nonpotassium maintenance blood solution between intermittent cardioplegia doses (modified integrated strategy) completely resuscitates the stressed neonatal heart, restoring myocardial, metabolic, and vascular function, (3) that the modified solution is equally effective delivered in an antegrade or retrograde fashion, and (4) that this method has been applied successfully to 72 hypoxic (stressed) pediatric patients, with excellent results.

Chronically hypoxic (cyanotic) patients have reduced ATP levels secondary to ischemic insults during times of 
increased stress (eg, tachycardia, exercise). ${ }^{2,6-8,10,11}$ To simulate the cyanotic child undergoing operative repair, piglets therefore underwent both hypoxic and ischemic stress. Although an acute stress does not exactly mimic chronic hypoxia, several studies have demonstrated similar changes with reoxygenation of acutely hypoxic piglets and chronically hypoxic infants. ${ }^{12,18-23}$ In addition, despite the absence of adaptation, we characterized almost identical changes in 21 cyanotic infants with the same biochemical tests as those used in our acute experimental studies. ${ }^{20}$ It is important to use stressed (hypoxic-ischemic) hearts when investigating cardioplegic strategies, because they are more sensitive to changes in protection. $1,5,8,9,16,17,20$ Consequently, our model provides information about the patients most vulnerable to postoperative dysfunction. This approach parallels the evolution of cardioplegia strategies in adults, where acute ischemia has been used to mimic the chronic clinical conditions of angina and cardiogenic shock. ${ }^{1}$

The hypoxic-ischemic stress produced a significant oxygen-derived free radical-mediated injury, resulting in cellular damage that was so severe that CPB could not be discontinued. However, warm induction was able to partially resuscitate the hypoxic-ischemic neonatal heart, and despite the addition of 70 minutes of ischemic arrest, intermittent infusions of cold blood cardioplegia preserved hemodynamic and metabolic function at levels identical to warm induction without further ischemia. Intermittent cardioplegia therefore effectively prevents any further myocardial damage, but is unable to improve the stress injury. Conversely, infusion of a maintenance solution of unmodified blood between intermittent cardioplegic infusions (standard integrated strategy) improved functional and metabolic recovery. However, this effect was maximized only if a modified (nonpotassium) blood solution was used for the maintenance infusions. This improvement was independent of the method of delivery, with antegrade and retrograde infusions resulting in similar recoveries. This implies that maintenance infusions of a cold modified solution do more than just limit ischemia during cardioplegic arrest, they also actively resuscitate the stressed heart, because a modified solution improved functional and metabolic recovery relative to piglets receiving warm induction without ischemia. This conclusion is further supported by the finding that a modified maintenance solution (modified integrated strategy) improved recovery to a greater extent than continuous infusions of unmodified blood (standard integrated strategy), despite the fact that both these approaches reduce ischemia equally by providing oxygenated blood during myocardial arrest.

Previously only warm blood cardioplegia has been demonstrated to have the ability to resuscitate the stressed heart. ${ }^{1,4}$ Normothermia is thought to be necessary to optimize the enzymatic reactions needed for cellular repair. Why such a dramatic improvement occurs when a modified maintenance solution is infused at $4{ }^{\circ} \mathrm{C}$ is unknown, but it suggests that the solution is working through a mechanism that is not dependent on enzymatic activity. It is possible that the same effect would have occurred if the modified solution had been infused under normothermic conditions. Keeping the heart warm is potentially dangerous, however, because it is less tolerant to ischemic intervals when the infusion are interrupted or if cardioplegic distribution is not adequate to all myocardial segments. Maintenance infusions were given for only half the time between cardioplegic infusions, to mimic the clinical situation in which infusions must occasionally be interrupted to optimize visualization needed for surgical repair. The maintenance infusions were always delivered at a measured pressure of 30 to $50 \mathrm{~mm} \mathrm{Hg}$, because infusion of intermittent cardioplegia at higher pressures $(>80 \mathrm{~mm} \mathrm{Hg}$ ) is detrimental to stressed neonatal hearts. ${ }^{24}$ These lower pressures $(30-50 \mathrm{~mm} \mathrm{Hg}$ ) are probably even more important with continuous delivery, because the heart is exposed to this pressure for a prolonged period. The modified solution used for the maintenance infusions was based on our multidose cardioplegia solution, but the potassium was removed to avoid postbypass hyperkalemia. ${ }^{1}$ Furthermore, potassium is probably not required, because the cold arrested heart tends to stay that way if it is maintained at $4^{\circ} \mathrm{C}$. ${ }^{1,4}$ To ensure myocardial quiescence, however, potassium cardioplegia is still given every $20 \mathrm{~min}-$ utes, or whenever the continuous infusions are interrupted, because the arrested heart can have small-amplitude ventricular fibrillation develop; this is not always visible but still results in increased oxygen consumption and ischemia. ${ }^{1,25}$ Whether any particular component in the modified solution is more important is unknown. Because each component was found to be important in multidose cardioplegic solutions, however, the same is probably true of the modified solution.

CVR was measured with each cardioplegic infusion to determine the effects of each strategy on vascular function. Vascular dysfunction can adversely affect myocardial protection by altering cardioplegic distribution. The coronary vasculature normally vasodilates after ischemia, resulting in a decrease in CVR. The CVR should therefore be reduced after the 20-minute ischemic stress, as well as between intermittent cardioplegic doses. However, the CVR was increased with warm induction and remained elevated with each intermittent cardioplegic infusion. This implies vascular dysfunction as a result of a vascular injury, as well as that this injury persists throughout the period of cardioplegic arrest. In contrast, the CVR progressively decreased with each cardioplegic infusion in hearts receiving integrated protection. This improvement was greatest in the group receiving maintenance infusions of a nonpotassium modified blood solution (modified integrated strategy). These infusions, however, should have had the opposite 
effect, because they reduce ischemia between cardioplegic doses so that the coronary vasculature should not need to vasodilate. This decrease in CVR therefore implies progressive repair of a vascular injury with normalization of vascular function. We cannot be certain that the normalization of CVR indicates repair of the vascular injury, because specific test of vascular function were not done after bypass. That is the most likely explanation, however, because CVR directly correlates with functional and metabolic recovery.

On the basis of these experimental results, we began using a modified integrated strategy whenever possible in both adult and pediatric patients, because this concept should be independent of age. We chose patients undergoing a Fontan or arterial switch procedure for this retrospective review only because these patients all received this method of protection. These two groups also allowed us to evaluate different methods of delivery and age groups, because the patients undergoing Fontan procedures were older and received antegrade delivery, whereas those undergoing arterial switch operations were neonates and received retrograde delivery. As in the experimental studies, the maintenance infusions were occasionally interrupted. However, they were only stopped when visualization was problematic, such as when working around the coronary sinus in Fontan procedures or the left main coronary artery in arterial switch operations. Despite the high-risk nature of these two groups, the results were excellent and support the clinical application and safety of this approach.

Relative to antegrade delivery, retrograde delivery provides superior perfusion of the vulnerable left ventricular subendocardium and septum, especially in the setting of coronary occlusion or ventricular hypertrophy. ${ }^{1,26-28}$ This study suggests that another reason to use retrograde cardioplegia is to provide cardioplegic delivery whenever frequent antegrade infusions are not possible (such as with arterial switch procedures). In contrast to adults, however, protection of the right ventricle is often more important in pediatric patients because of the frequent problems of right ventricular hypertrophy and postoperative pulmonary hypertension. ${ }^{2,6}$ The pediatric surgeon must therefore be careful about relying solely on retrograde delivery, because it may not supply adequate nutritive flow to the right ventricular free wall, especially at normothermia. ${ }^{26-28}$ This was the reason that the terminal warm reperfusate (hot shot) was always delivered antegrade, because this helps to compensate for any inadequacies in right ventricular free wall protection by repairing cellular damage that may have occurred during cold cardioplegic arrest.

In summary, this study demonstrated the advantages of infusing a modified (nonpotassium) blood maintenance solution whenever possible, not only to limit ischemia but to help resuscitate the damaged (stressed) heart, thus improving postoperative myocardial, metabolic, and vascu- lar function. These infusions are equally effective whether delivered in an antegrade or retrograde fashion and have been used successfully for high-risk patients. Because the stressed (hypoxic) heart is more sensitive to ischemia as well as more predisposed toward post myocardial dysfunction, surgeons should consider incorporating a modified integrated strategy into their clinical practice. ${ }^{2,6-9}$

We acknowledge Dr Gerald D. Buckberg for his collaboration and consultation, Ms Katherine Tubeszewski, RN, MSN, for her help with clinical data collection, and the organizational and secretarial assistance of Ms Tina Green.

\section{References}

1. Buckberg GD, Allen BS. Myocardial protection management during adult cardiac operations. In: Baue AE, Geha AS, Hammond GL, Laks H, Naunheim KS, editors. Glenn's thoracic and cardiovascular surgery. 6th ed. Stamford (CT): Appleton \& Lange; 1995. p. 1653-87.

2. Castaneda AR, Jonas RA, Mayer JE Jr, Hanley FL. Myocardial preservation in the immature heart. In: Castaneda AR, Jonas RA, Mayer JE Jr, Hanley FL, editors. Cardiac surgery of the neonate and infant. Philadelphia: WB Saunders; 1994. p. 41-54.

3. Buckberg GD, Beyersdorf F, Allen BS, Robertson JR. Integrated myocardial management: background and initial application. J Card Surg. 1995;10:68-89.

4. Allen BS, Evans-Murcia D, Hartz RS. Integrated cardioplegia allows complex valve repairs in all patients. Ann Thorac Surg. 1996;62:23-30.

5. Bolling KS, Kronon M, Allen BS, Wang T, Ramon S, Feinberg H. Myocardial protection in normal and hypoxically stressed neonatal hearts: the superiority of blood versus crystalloid cardioplegia. $J$ Thorac Cardiovasc Surg. 1997;113:994-1005.

6. Hammon JW Jr. Myocardial protection in the immature heart. Ann Thorac Surg. 1995;60:839-42.

7. Fujiwara T, Kurtts T, Anderson W, Heinke J, Mayer J. Myocardial protection in cyanotic neonatal lambs. J Thorac Cardiovasc Surg. 1988; 96:700-10.

8. Silverman N, Kohler J, Levitsky S, Pavel D, Fang R, Feinberg H. Chronic hypoxemia depresses global ventricular function and predisposes to depletion of high energy phosphates during cardioplegic arrest: implications for surgical repair of cyanotic congenital heart defects. Ann Thorac Surg. 1984;37:304-8.

9. del Nido PJ, Mickle DA, Wilson GJ, Benson LN, Weisel RD, Coles $\mathrm{JG}$, et al. Inadequate myocardial protection with cold cardioplegic arrest during repair of tetralogy of Fallot. J Thorac Cardiovasc Surg. 1988;95:223-9.

10. Graham TP Jr, Erath HG Jr, Buckspan GS, Fisher RD. Myocardial anaerobic metabolism during isoprenaline infusion in a cyanotic animal model: possible cause of myocardial dysfunction in cyanotic congenital heart disease. Cardiovasc Res. 1979;13:401-6.

11. Boucek RJ Jr, Kasselberg AG, Boerth RC, Parrish MD, Graham TP Jr. Myocardial injury in infants with congenital heart disease: evaluation by creatinine kinase MB isoenzyme analysis. Am J Cardiol. 1982;50:129-35.

12. Bolling KS, Halldorsson A, Allen BS, Rahman SK, Wang T, Kronon $\mathrm{M}$, et al. Prevention of the hypoxic/reoxygenation injury using a leukocyte depleting filter. J Thorac Cardiovasc Surg. 1997;113:1081-90.

13. Rebeyka I, Hanan SA, Borges MR, Lee KF, Yeh T Jr, Tuchy GE, et al. Rapid cooling contracture of the myocardium. J Thorac Cardiovasc Surg. 1990;100:240-9.

14. Kronon MT, Allen BS, Rahman SK, Wang T, Rayyab NA, Bolling KS, et al. Reducing postischemic reperfusion damage in neonates using a terminal warm substrate enriched blood cardioplegic reperfusate. Ann Thorac Surg. 2000;70:765-70.

15. Follette D, Fey K, Buckberg GD, Helly MA, Steed DL, Foglia R, et al. Reducing postischemic damage by temporary modification of reperfusate calcium, potassium, $\mathrm{pH}$, and osmolarity. $J$ Thorac Cardiovasc Surg. 1981;82:221-38. 
16. Bolling KS, Kronon M, Allen BS, Ramon S, Wang T, Hartz R, et al. Myocardial protection in normal and hypoxically stressed neonatal hearts: the superiority of hypocalcemic versus normocalcemic blood cardioplegia. J Thorac Cardiovasc Surg. 1996;112:1193-201.

17. Kronon M, Allen BS, Bolling KS, Rahman SK, Wang T, Maniar H, et al. The role of cardioplegic induction temperature and amino acid enrichment in neonatal myocardial protection. Ann Thorac Surg. 2000;70:756-64.

18. Teoh KH, Mickle DA, Weisel RD, Li R, Tumiati L, Coles JG. Effect of oxygen tension and cardiovascular operations on the myocardial antioxidant enzyme activities in patients with tetralogy of Fallot and aorta-coronary bypass. J Thorac Cardiovasc Surg. 1992;104:159-64.

19. del Nido PJ, Mickle DA, Wilson G, Benson LN, Cole JG, Trusler GA. Evidence of myocardial free radical injury during elective repair of tetralogy of Fallot. Circulation. 1987;76:174-9.

20. Kronon M, Allen BS, Halldorsson A, Rahman SK, Wang T, Ilbawi M. Dose dependency of L-arginine in neonatal myocardial protection: the nitric oxide paradox. J Thorac Cardiovasc Surg. 1999;118:655-73.

21. Allen BS, Rahman SK, Ilbawi M, Feinberg H, Bolling KS, Kronon M. The detrimental effects of cardiopulmonary bypass in cyanotic infants: preventing the reoxygenation injury. Ann Thorac Surg. 1997; 64:1381-8.

22. Martin G, Short B, Abbott C, O'Brien A. Cardiac stun in infants undergoing extracorporeal membrane oxygenation. J Thorac Cardiovasc Surg. 1991;101:607-11.

23. Buckberg GD. Studies of hypoxemic/rexoygenation injury: I. Linkage between cardiac function and oxidant damage. J Thorac Cardiovasc Surg. 1995;110:1164-70.

24. Kronon MT, Bolling KS, Allen BS, Rahman SK, Wang T, Feinberg H. The importance of monitoring cardioplegia infusion pressure in neonatal myocardial protection. Ann Thorac Surg. 1998;66:1358-64.

25. Landymore RW, Marvle AE, MacAulay MA, Li QY, Fris J. Oxygenated cardioplegia ameliorates the adverse effects of small amplitude electrical recording of activity on myocardial, metabolic and functional recovery. Eur J Cardiothorac Surg. 1991;5:37-40.

26. Allen BS, Winkelmann JW, Hanafy HM, Hartz RS, Bolling KS, Ham JW, et al. Retrograde cardioplegia does not perfuse the right ventricle. J Thorac Cardiovasc Surg. 1995;109:1116-26.

27. Gates RN, Laks H, Drinkwater DC, Pearl J, Zarazoga AM, Kaczer E, et al. The microvascular distribution of cardioplegic solution in the piglet heart-retrograde vs. antegrade delivery. $J$ Thorac Cardiovasc Surg. 1993;105:845-53.

28. Partington MT, Acar C, Buckberg G, Julia P, Kofsky ER, Bugyi H. Studies of retrograde cardioplegia. II. Nutritive blood flow distribution in normal and jeopardized myocardium. J Thorac Cardiovasc Surg. 1989;97:613-22.

\section{Discussion}

Dr David Clarke (Denver, Colo). Congratulations to Allen and colleagues for a meticulous and obviously carefully constructed experimental study and some obviously superb clinical results.

I would like to address three areas. The first involves the induction of the ischemic stress before the cardioplegic protection. You seem to have gone to a great deal of effort to simulate the clinical situation by limiting your continuous infusion to only half the period to allow time for possibly complex portions of the repair. Yet at the beginning of your protocol you subjected the hearts to 20 minutes of unprotected warm ischemia, which is something that $\mathrm{I}$ at least try to avoid in the clinical situation. Perhaps you could comment on the rationale for this approach.

Dr Allen. The hypoxic ischemic stress was our way of simulating a cyanotic (hypoxic) infant undergoing operative repair. We first subjected the piglets to 1 hour of hypoxia. However, our model of acute hypoxia does not result in any ischemia or ATP depletion, whereas most cyanotic children have reduced ATP lev- els at the time of surgery as a result of ischemic insults during times of increased stress (eg, tachycardia and exercise). We therefore added a 20-minute ischemic insult to more closely simulate the chronically hypoxic (cyanotic) patient. We recognize that this acute stress (hypoxia-ischemia) does not exactly mimic the chronically hypoxic (cyanotic) child. However, several studies have demonstrated similar changes after reoxygenation of the chronically hypoxic infant, and we recently documented an identical injury in 21 cyanotic infants with the same biochemical tests as those used in our acute experimental studies. It is important to test cardioplegic protocols in stressed (hypoxic) hearts, because they are more sensitive to changes in myocardial protection and are the most vulnerable to postoperative dysfunction. This is why adult studies usually subject the heart to an acute ischemic stress by crossclamping the aorta, even though this does not exactly mimic the clinical conditions of chronic ischemia or heart failure.

Dr Clarke. The next issue involves the flows and volumes that were used in the administration of the various solutions. In your article you indicated that you tried to maintain certain pressures in the aortic root and certain pressures in the coronary sinus, and you also indicated the durations of these infusions of the warm cardioplegia, the cold cardioplegia, and your modified solution. I could probably do the math, because you did mention CVR, but I would really appreciate it if you would tell me how much volume this requires and give your flow rates. I have tried in the operating room to give antegrade cardioplegia continuously on numerous occasions at low flow rates and found that it is almost impossible to keep the aortic valve closed, and the cardioplegic solution therefore runs off in the ventricular vent. With higher flows, it would seem to me that you would have a great deal of difficulty doing some of your more complex transatrial repairs, such as atrioventricular septal defect or transatrial tetralogy repairs. Would you like to comment on this?

Dr Allen. We usually do not measure cardioplegia volumes but deliver cardioplegic solution at a given pressure $(30-50 \mathrm{~mm} \mathrm{Hg}$ ) across a specific time interval, because oxygen and nutrients are taken up with time, not by a specific dose. In these studies this usually resulted in a flow rate into the aorta or coronary sinus of around $50 \mathrm{~mL} / \mathrm{min}$. I believe that it is important to always measure the cardioplegic infusion pressure, because high pressures can be detrimental, especially to hypoxic tissue, whereas low pressures signify inadequate delivery. A low infusion pressure is often due to a technical problem. If the cardioplegic delivery pressure remains low despite adequate flows, the surgeon should first try to correct the underlying cause. Simply giving a set volume that is inadequately delivered yields a false sense of security that the cardioplegic solution is protecting the heart. In cases of severe aortic insufficiency, I would not persist in trying to keep the aortic valve closed and the pressure adequate. In these cases I would either open the aorta and give cardioplegic soltuion directly into the coronary arteries or switch to retrograde delivery. Finally, continuous infusions should only be given when they do not impair visualization. During these times, we rely on intermittent cardioplegia alone.

Dr Clarke. My last question is somewhat related. At the flows that I believe are required to maintain the pressures that you indicated, you are probably giving a larger amount of solution. I have used continuous retrograde cardioplegia for a number of years at 1 $\mathrm{mL} \cdot \mathrm{kg}^{-1} \cdot \mathrm{min}^{-1}$ and have not really had serious problems with 
hyperkalemia. It seems to me that what you are doing here is a combination of potassium cardioplegia and magnesium cardioplegia. I wonder whether there is a significant advantage to having hypermagnesemia in the early postoperative period as opposed to hyperkalemia. Perhaps you can comment on this. Have you measured magnesium levels in the experimental situation or in the clinical situation?

Dr Allen. Yes, we have used a modified integrated strategy with this type of solution clinically for several years in both adult and pediatric patients. We also currently add magnesium to our intermittent cardioplegic infusions. To the best of my knowledge we have not had a problem with high postoperative magnesium levels, and Hearse* has shown that cardioplegic solutions with magnesium levels as high as $16 \mathrm{mEq} / \mathrm{L}$ are safe. We use a magnesium-free bypass prime, and several studies have shown that there is depletion of intracellular magnesium with initiation of $\mathrm{CPB}$, as well as during cardioplegic arrest. In some respects what we are doing by adding magnesium to the cardioplegic and maintenance solutions is restoring the intracellular magnesium that would normally be depleted by CPB. An increased magnesium level should not be problematic, because it prevents arrhythmias, and any adverse myocardial effects can easily be reversed with calcium. For this reason, we believe it is extremely important to normalize ionic calcium levels in the upper range of normal before discon-

* Hearse DJ, Stewart DA, Braimbridge MV. Myocardial protection during ischemic cardiac arrest: the importance of magnesium in cardioplegic infusates. J Thorac Cardiovasc Surg. 1978;75:877-85. tinuing bypass, especially if a patient receives a large amount of cardioplegic solution.

Dr John Hawkins (Salt Lake City, Utah). Were your study animals perfused at normothermia or hypothermia?

Dr Allen. The temperature was reduced to $25^{\circ} \mathrm{C}$ immediately on initiation of $\mathrm{CPB}$, and the piglets were rewarmed about 16 minutes before removal of the aortic crossclamp. We began rewarming the animals approximately 12 minutes before the terminal warm reperfusate.

Dr Hawkins. So the body temperature was kept cold the whole time.

Dr Allen. Correct.

Dr Hawkins. With intermittent cardioplegia you do get some myocardial warming if the body temperature is warm, and I wonder what role that simple cooling had in this. In other words, the continuous infusion simply kept the heart colder and may not have much to do with the mixture versus intermittent cardioplegia with a body temperature that was somewhat warm.

Dr Allen. No, this does not explain the findings. When we gave a warm induction and then removed the aortic clamp, there was only $40 \%$ recovery of overall myocardial function, despite no cardioplegic ischemia. Furthermore, recovery was still not complete when we infused cold unmodified blood between cardioplegic infusions (standard integrated), despite the fact that the heart was kept cold and perfused with an oxygenated solution. In contrast, there was complete recovery if a cold modified solution was used for the maintenance infusions. Thus, neither temperature nor oxygen alone explains our results. Instead, by some unknown mechanism a cold modified solution allows the heart to repair the hypoxic-ischemic stress. 